\title{
Cerebral Palsy: Current Opinions on Definition, Epidemiology, Risk Factors, Classification and Treatment Options
}

This article was published in the following Dove Press journal: Neuropsychiatric Disease and Treatment

\author{
Małgorzata Sadowska' \\ Beata Sarecka-Hujar (D) ${ }^{2}$ \\ Ilona Kopyta iD ${ }^{3}$ \\ 'Department of Paediatrics and \\ Developmental Age Neurology, Upper \\ Silesian Child Health Centre, Katowice, \\ Poland; ${ }^{2}$ Department of Basic Biomedical \\ Science, School of Pharmacy with the \\ Division of Laboratory Medicine, Medical \\ University of Silesia in Katowice, \\ Sosnowiec, Poland; ${ }^{3}$ Department of \\ Pediatric Neurology, School of Medicine \\ in Katowice, Medical University of Silesia \\ in Katowice, Katowice, Poland
}

Correspondence: Ilona Kopyta Department of Pediatric Neurology, School of Medicine in Katowice,Medical University of Silesia in Katowice, Katowice, Poland

Email ilonakopyta@autograf.pl

\begin{abstract}
Cerebral palsy (CP) is one of the most frequent causes of motor disability in children. According to the up-to-date definition, $\mathrm{CP}$ is a group of permanent disorders of the development of movement and posture, causing activity limitations that are attributed to non-progressive disturbances that occurred in the developing foetal or infant brain. The CP definition has evolved over time; the problem is aetiologically and clinically very heterogeneous. According to European data, the average frequency of $\mathrm{CP}$ is 2.08 per 1000 live births, but in the group of children born with a body weight below $1500 \mathrm{~g}$, the frequency is 70 times higher when compared with the group of children with a body weight over $2500 \mathrm{~g}$ at birth. The risk factors for CP can be divided into preconception, prenatal, perinatal and postnatal ones. CP commonly co-exists with epilepsy, in particular drug-resistant epilepsy, but also with mental retardation, visual and hearing impairment, as well as feeding and behavioral disorders. The degree of motor problem varies from mild to very severe making the child totally dependent on caregivers. Cerebral palsy is divided into forms depending on the type of motor disorders which dominate the clinical presentation; the traditional classifications by Ingram and Hagberg have now been replaced by the Surveillance of Cerebral Palsy in Europe classification which divides CP into spastic, dyskinetic and ataxic forms. Although cerebral palsy is a clinical diagnosis, modern diagnostic imaging provides information that allows the division of the results of magnetic resonance imaging in children with cerebral palsy into five groups according to the magnetic resonance imaging classification system. Just as the clinical presentation and the factors predisposing for $\mathrm{CP}$ are very diverse, treatment is also a very complex problem. Modern treatment of spasticity includes both botulinum toxin therapies and surgical techniques, eg, rhizotomy. The authors present current views on definitions, risk factors, diagnostics and treatment of $\mathrm{CP}$ as well as comorbid problems, eg, drug-resistant epilepsy.
\end{abstract}

Keywords: cerebral palsy, CP, risk factors, comorbidities, epilepsy, malnutrition, mental retardation, treatment

\section{Introduction}

Cerebral palsy (CP) is not a defined, separate disease classification, but an umbrella term encompassing aetiologically diverse symptoms, which change with age. The term "cerebral paralysis" was used for the first time more than 170 years ago, by the English orthopaedic surgeon William Little, who correlated a difficult labour and neonatal hypoxia with limb spasticity and consequential musculoskeletal deformities. ${ }^{1}$

Over the years, the definition of cerebral palsy has been repeatedly changed. ${ }^{2-4}$ According to the current definition, developed by an international team of experts, cerebral palsy is a group of permanent, but not unchanging, disorders of movement and/or posture and of motor function, which are due to a non-progressive 
interference, lesion, or abnormality of the developing/ immature brain. ${ }^{5-7}$ The diagnosis of cerebral palsy is mainly based on motor function and posture disorders that occur in early childhood and persist until the end of life; they are non-progressive, but change with age. Motor function disorders, which are the core symptoms of cerebral palsy, are frequently accompanied by other dysfunctions, such as: sensation, perceptual, cognitive, communication and behavioural disorders, epilepsy, and secondary musculoskeletal disorders. ${ }^{6-8}$

Many metabolic and non-progressive genetic disorders may present with motor dysfunction resembling cerebral palsy. Such disorders are often characterized as CP mimics. ${ }^{9-12}$

There are reports in the literature of inborn errors of metabolism that present as CP mimics; a large proportion of these diseases are treatable such that neurological damage can either be reversed or prevented. ${ }^{9}$ The primary aetiology of a cerebral palsy syndrome should always be identified if possible. This is particularly important in the case of genetic or metabolic disorders that have specific disease-modifying treatment. ${ }^{11}$ Making a precise diagnosis of a metabolic or genetic disorder has important implications for the possibility of treatment, accurate prognosis and genetic counselling. ${ }^{11,12}$ The aim of the present literature review was to discuss current views on definitions, risk factors, diagnostics and treatment of $\mathrm{CP}$ as well as comorbid problems, eg, drug-resistant epilepsy.

\section{Frequency of Cerebral Palsy Incidence}

The average incidence of cerebral palsy is estimated to range between 1.5 and 3.0 per 1000 live births; these values change among selected groups of patients, depending on various risk factors. ${ }^{8}$ A huge role in the compilation of epidemiological data concerning some of the European countries was played by Surveillance of Cerebral Palsy in Europe (SCPE), containing registers of ill children from different European centres, which was established in 1998 using funds from the European Commission. SCPE was created due to the necessity of standardizing and harmonizing the definitions of cerebral palsy as well as the inclusion and exclusion criteria, so that researchers and practitioners dealing with cerebral palsy could use a "common" language. The activity of SCPE was aimed at creating a uniform database, initiating cooperation in research projects, gaining a better understanding of $\mathrm{CP}$ causes and improving the standards of care for children with cerebral palsy. ${ }^{7}$ Initially, SCPE was composed of 14 centres in eight European countries; in the following years, it was increased to include additional centres. ${ }^{7}$ Currently SCPE has 25 active centres in 20 European countries: Austria, Belgium, Croatia,
Denmark, France, Greece, Spain, Ireland, Iceland, Latvia, Malta, Germany, Norway, Portugal, Slovenia, Switzerland, Sweden, Hungary, the United Kingdom and Italy. SCPE work is carried out by specialists dealing with $\mathrm{CP}$ issues in various fields, ie, epidemiologists, paediatric neurologists, neonatologists, paediatricians, gynaecologists, geneticists, surgeons, orthopaedists, public health specialists, physiotherapists, occupational therapists, speech and language therapists, nutritionists and social workers.

SCPE work has contributed to the analysis of CP incidence at different time intervals, in particular depending on the birth weight. ${ }^{13,14}$ Data from the register of 6500 children with CP from 13 European centres, which were published in 2002 and concerned the years 1980-1990, allowed for estimating the average incidence of $\mathrm{CP}$ as 2.08 per 1000 live births; however, the incidence among premature babies with birth weight below 1500 grams was more than 70 times higher than in children with birth weight of 2500 grams and more. ${ }^{13}$

Another study concerned the analysis of CP incidence in infants born in the years 1980-1996 with birth weight below $1500 \mathrm{~g}$ in 16 European countries. CP incidence in this group of children decreased from 60.6 per 1000 live births in 1980 to 39.5 per 1000 live births in $1996 .^{14}$

Detailed data on CP incidence depending on a baby's maturity at birth was provided by the meta-analysis of research results published in the years 1985-2006, conducted by Belgian researchers. ${ }^{15}$ The results were compared for four groups: premature infants born before the 28th week of pregnancy, those born between the 28th-31st week of pregnancy, those born between the 32nd-36th week of pregnancy, and babies born later than the 37 th week of pregnancy. The incidence of CP ranged from 146 cases per 1000 live births in the first group of children to 1.13 cases per 1000 live births in the group of children born after the 37th week of pregnancy. In the remaining two groups, these indicators reached 62/1000 (for children born between the 28th-31st week of pregnancy) and 7/ 1000 (for infants born between the 32nd-36th week of pregnancy), respectively. In 2013, Canadian researchers, Oskoui et al, conducted a meta-analysis of $\mathrm{CP}$ incidence based on a subject literature review from the years 1990-2005, taking into consideration both the birth weight and foetal age of infants. ${ }^{16}$ The general incidence of CP was established as 2.11/1000 live births; the highest indicator was noted for babies whose birth weight ranged from $1000 \mathrm{~g}$ to $1499 \mathrm{~g}(59.18 / 1000$ live births) and for babies born before the 28th week of pregnancy (111.8/1000 live births).

The multi-centre study based on SCPE registers, published in 2016, which concerned the years 1980-2003, showed 
a downward trend in CP incidence. ${ }^{17}$ The general incidence of cerebral palsy dropped from 1.90/1000 live births in 1980 to $1.77 / 1000$ live births in 2003. The downward trend was also noted in the case of babies with a very low birth weight (VLBW), ie, 1000-1499 g (a decrease from 70.9/1000 to $35.9 / 1000$ ), and babies with a low birth weight (LBW), ie, 1500-2499 g (a decrease from 8.5/1000 to 6.2/1000). According to the authors, in children with birth weight over $2499 \mathrm{~g}$, a statistically insignificant downward trend (from 1.17 to $0.89 / 1000$ ) could be observed. The incidence of CP in babies with an extremely low birth weight (ELBW), ie, below $1000 \mathrm{~g}$, was at a stable level - an average of 42.4/1000 live births. During that time, however, the rates of both birth and survival of premature babies with ELBW clearly increased owing to considerable advances in perinatology (modern methods of prenatal diagnostics, in-utero transport, intensive neonatal care). ${ }^{17}$

\section{Aetiopathogenesis and Risk Factors for $\mathbf{C P}$}

$\mathrm{CP}$ aetiology is complex. For more than 100 years, it was believed that the vast majority of $\mathrm{CP}$ cases were related to infant brain hypoxia during labour or in the perinatal period, thus CP incidence was considered to be a measure of obstetric and neonatal care quality. However, despite medical care intensification in these areas, CP incidence remained unchanged. ${ }^{18}$ Epidemiological studies conducted worldwide in recent years have contributed to a better understanding of the factors that have a significant impact on $\mathrm{CP}$ incidence. The results of these investigations indicate that, contrary to the previous belief, perinatal pathology is of less importance in $\mathrm{CP}$ aetiology. Prenatal factors seem to be responsible for nearly $75 \%$, whereas infant and neonatal period risk factors account for $10 \%$ to $18 \%$ of all CP cases. ${ }^{18}$

A number of factors may cause damage to the central nervous system (CNS) at an early stage of its development. The risk factors fall into the following categories: preconception, concerning the broadly defined health and living conditions of the mother; prenatal, which are related to the course of pregnancy; perinatal; as well as risk factors in the neonatal and infant period. ${ }^{18-23}$ Figure 1 lists risk factors associated with each of these categories.

One of the major $\mathrm{CP}$ incidence risk factors is prematurity. The frequency and severity of neurodevelopmental disorders are correlated with pregnancy duration - the shorter the pregnancy, the more severe the disorders. Birth weight in premature babies is another risk factor. ${ }^{13,16}$

\section{Clinical Presentation of Cerebral Palsy}

The clinical presentation of cerebral palsy is varied. There are many classifications of this heterogeneous group of motor disorders. The most frequently applied are the ones proposed by Ingram (in 1955) and Hagberg (in 1976). ${ }^{24,25}$ Ingram's classification provides a comprehensive definition of both the type of neurological syndrome and its location, as well as the severity of symptoms. It includes the following clinical types: diplegia, hemiplegia, bilateral hemiplegia (tetraplegia) ataxia, dyskinesia, and mixed types. Characteristics of these clinical types are presented in Table 1 . In all the types, movement disorders can be slight, moderate or severe. ${ }^{24}$ In turn, classification according to Hagberg takes into account: spastic syndromes, extrapyramidal (dyskinetic) syndromes, and ataxia (Table 1). On the other hand, SCPE, aiming to standardize $\mathrm{CP}$ classification, has proposed a simple classification of patients, dividing them into three major groups: spastic (unilateral or bilateral spastic), dyskinetic (dystonic or choreathetotic) and ataxic (Table 1). ${ }^{7}$ If one of the subgroups is difficult to identify, it is advisable to use the general term of dyskinetic CP.

In the case of mixed disorders, achild with $\mathrm{CP}$ should by classified according to the SCPE guidelines, on the basis of the predominant symptoms. ${ }^{7}$ SCPE recommends asimple classification of spastic types; its registers, however, contain data concerning the severity of motor disorders in both lower and upper limbs, using the evaluation result on the relevant scales: the Gross Motor Function Classification System (GMFCS) as well as Bimanual Fine Motor Function (BFMF) and the Manual Ability Classification System (MACS). Evaluation of achild's functioning on the above scales allows for obtaining information on the severity of motor disorders and affected limbs. ${ }^{7,26-29}$

\section{Evaluation of the Severity of Motor Disorders in CP}

To evaluate the severity of motor disorders in the course of $\mathrm{CP}$, various scales are applied. One of the most common and easyto-use is the GMFCS, developed by Palisano et al. ${ }^{26}$ This scale is based on the evaluation of a child's independence when performing basic motor functions, such as walking or moving with the aid of ancillary equipment: crutches, walking frames, and wheelchairs. Evaluation of a patient on this scale allows for their classification into a particular level of performance (Table 2). The GMFCS scale is modified according to children's ages. There are several age categories: up to 2 years of age, 2-4 years, 4-6 years, 6-12 years and 12-18 years of age. ${ }^{27}$ 


\begin{tabular}{|c|c|c|c|}
\hline & $\mathbf{R i}$ & bral palsy & \\
\hline $\begin{array}{l}\text { Pre-conception: } \\
\text { - mother's systemic } \\
\text { diseases, } \\
\text { - drugs and stimulants } \\
\text { used, malnutrition, } \\
\text { - poisonings, infections } \\
\text { - immune system } \\
\text { disorders preceding the } \\
\text { pregnancy, } \\
\text { - physical and chemical } \\
\text { factors, } \\
\text { - impaired fertility, } \\
\text { treatment of infertility, } \\
\text { - spontaneous abortions, } \\
\text { - socio-economic factors }\end{array}$ & $\begin{array}{l}\text { Prenatal: } \\
\text { - vaginal bleeding, } \\
\text { - abnormalities of the } \\
\text { placenta, placental } \\
\text { abruption, } \\
\text { - multiple pregnancy, } \\
\text { - mother's systemic disease } \\
\text { during pregnancy, } \\
\text { intrauterine infections, } \\
\text { - abnormal pulse of the } \\
\text { foetus, } \\
\text { - tocolytic drugs, } \\
\text { - toxaemia, } \\
\text { - oligohydramnios, } \\
\text { polyhydramnios, } \\
\text { - intrauterine suppression } \\
\text { of development, } \\
\text { - intrauterine hypoxia, } \\
\text { - premature rupture of } \\
\text { membranes, } \\
\text { - assisted reproductive } \\
\text { technology, among others } \\
\text { fitro fertilization }\end{array}$ & $\begin{array}{l}\text { Perinatal: } \\
\text { - premature birth, } \\
\text { - C-section, } \\
\text { - vacuum-assisted } \\
\text { delivery, } \\
\text { - forceps delivery, } \\
\text { - delivery after due } \\
\text { date, } \\
\text { - labour induction, } \\
\text { - prolonged labour, } \\
\text { - asphyxia, } \\
\text { - meconium } \\
\text { aspiration syndrome }\end{array}$ & $\begin{array}{l}\text { Neonatal and infant } \\
\text { period: } \\
\text { - respiratory distress } \\
\text { syndrome, } \\
\text { - artificial respiratory } \\
\text { support - respiratory } \\
\text { therapy, oxygen } \\
\text { therapy, } \\
\text { - infections, especially } \\
\text { generalized ones, } \\
\text { meningitis, } \\
\text { - hyperbilirubinemia, } \\
\text { - hypoglycaemia, } \\
\text { - hypothyroxinaemia, } \\
\text { - intracranial } \\
\text { haemorrhages, } \\
\text { - neonatal } \\
\text { convulsions }\end{array}$ \\
\hline
\end{tabular}

Figure I Potential risk factors for cerebral palsy. Data from references I8-23.

The GMFCS lacks a precise description of hand dexterity. One of the systems for evaluating both hands' function depending on the dexterity of the other hand is the BFMF (Bimanual Fine Motor Function) scale; another tool is the MACS (Manual Ability Classification System). ${ }^{28,29}$

\section{Cerebral Palsy Diagnostics Procedures}

Diagnosis of cerebral palsy is based on clinical presentation, a precise interview concerning the pregnancy, labour, neonatal and infant period, the course of development and the current performance of the child's motor functions. Additional examinations can help in CP diagnosis.

\section{Neuroimaging Examination}

Important information is provided by neuroimaging examination, ie, brain ultrasonography in infants, computer tomography in older children, and in particular, magnetic resonance imaging (MRI) of the brain. MRI can be conducted for foetuses and prematurely born babies. The results of imaging studies using the MRI method demonstrate abnormalities in more than $80 \%$ of patients with $\mathrm{CP} .{ }^{30} \mathrm{MRI}$ 
Table I Clinical classifications of cerebral palsy (CP) according to data from Balf and Ingram (1955), ${ }^{24}$ Hagberg et al (I976) ${ }^{25}$ and Surveillance of Cerebral Palsy in Europe (SPCE) ${ }^{7}$

\begin{tabular}{|c|c|}
\hline Type & Characteristics \\
\hline \multicolumn{2}{|l|}{ Ingram's Classification } \\
\hline Diplegia & $\begin{array}{l}\text { Spastic paresis occurs mainly in lower limbs, three or four limbs (this type also includes quadriparesis syndromes, } \\
\text { in which lower limb paresis prevails over upper limb paresis) }\end{array}$ \\
\hline Hemiplegia & Spastic paresis is unilateral (right- or left-sided) with the predominance of the upper or lower limb \\
\hline $\begin{array}{l}\text { Bilateral hemiplegia } \\
\text { (tetraplegia) }\end{array}$ & $\begin{array}{l}\text { Spastic tetraparesis with the predominance of upper limb paresis (the most severe type of cerebral palsy in terms } \\
\text { of severity of motor disability as well as co-existing problems) }\end{array}$ \\
\hline Ataxia & $\begin{array}{l}\text { Muscle tension is reduced, accompanied by hand-eye coordination disorders; this type can be bilateral or with the } \\
\text { predominance of one side of the body }\end{array}$ \\
\hline Dyskinesia & $\begin{array}{l}\text { dystonic, athetosic, choreic type of } \mathrm{CP} \text {, accompanied by trembling or manifesting itself in frequent changes of } \\
\text { muscle tone. This type can occur in one limb, in one side of the body, or in three or four limbs }\end{array}$ \\
\hline Mixed types & the above-mentioned characteristics in various combinations \\
\hline \multicolumn{2}{|l|}{ Hagberg's Classification } \\
\hline Spastic syndromes & $\begin{array}{l}\text { Resulting from the damage of brain centres and tracks controlling a given activity: } \\
\text { monoparesis } \\
\text { hemiparesis } \\
\text { triparesis } \\
\text { tetraparesis } \\
\text { diplegia spastica }\end{array}$ \\
\hline $\begin{array}{l}\text { Extrapyramidal (dyskinetic) } \\
\text { syndromes }\end{array}$ & $\begin{array}{l}\text { Related to subcortical structure damage, characterized by various involuntary movements and generalized muscle } \\
\text { stiffness with scarce movements }\end{array}$ \\
\hline Ataxia & $\begin{array}{l}\text { Resulting from cerebellum damage, characterized by generalized hypotension, trembling, and motor coordination } \\
\text { disorders. }{ }^{21}\end{array}$ \\
\hline \multicolumn{2}{|l|}{ SCPE classification } \\
\hline Spastic type & $\begin{array}{l}\text { Characterized by enhanced muscle tension, hyperreflexia and pathological reflexes; it is split into unilateral spastic } \\
\text { and bilateral spastic, without further division into diplegia, tri- or tetraplegia }\end{array}$ \\
\hline Dyskinetic type & $\begin{array}{l}\text { Patients perform involuntary, uncontrolled, repetitive, sometimes stereotypical movements; muscle tension, which } \\
\text { can be both increased or decreased, and frequently changes over time. In this type, The following are identified by } \\
\text { SCPE: } \\
\text { - dystonic CP with a predominant faulty posture and enhanced muscle tension (so-called hypertonic-hypokinetic) } \\
\text { - choreoathetotic CP: this type is characterized by quick, uncontrolled, violent, frequently "fragmenting" } \\
\text { movements which overlap slow, constantly changing "twisting" movements; tension is usually changeable, } \\
\text { predominantly lowered (so-called hypotonic-hyperkinetic) }\end{array}$ \\
\hline Ataxic type & $\begin{array}{l}\text { Related to motor coordination loss, which results in ataxia, movements smoothness, and trembling; in this type of } \\
\mathrm{CP} \text { lowered muscle tension is predominant }\end{array}$ \\
\hline
\end{tabular}

Abbreviations: CP, cerebral palsy; SCPE, Surveillance of Cerebral Palsy in Europe.

examination reveals anatomic anomalies characteristic of particular CP types; it also allows for a better understanding of pathogenesis, brain damage aetiology and structuralfunctional dependencies in CP. Work conducted by SCPE has led to the establishment of a system of MRI results classification (magnetic resonance imaging classification system, MRICS) for children with cerebral palsy. Recommendations for this classification system were published online in 2016, and then printed in $2017 .{ }^{30}$ The aim of the MRICS is to enable simple interpretation and classification of brain MRI results by both clinicians and other specialists dealing with CP patients. According to MRICS, brain 
Table 2 Classification into a particular level of performance according to data from the Gross Motor Function Classification System (GMFCS) ${ }^{26}$

\begin{tabular}{|l|l|}
\hline $\begin{array}{l}\text { Level of } \\
\text { Performance }\end{array}$ & Characteristics \\
\hline I & The patient can walk freely \\
\hline II & $\begin{array}{l}\text { The patient walks on their own with certain } \\
\text { (slight) limitations }\end{array}$ \\
\hline III & The patient walks using ancillary equipment \\
\hline IV & $\begin{array}{l}\text { The patient can move on their own, but with } \\
\text { certain limitations; he/she can use an electric } \\
\text { wheelchair }\end{array}$ \\
\hline V & $\begin{array}{l}\text { The patient is not able to move on their own; he/ } \\
\text { she is transported in a wheelchair by a carer }\end{array}$ \\
\hline
\end{tabular}

images in children with $\mathrm{CP}$ are classified into five main groups: A. Maldevelopments; B. Predominant white matter injury; C. Predominant grey matter injury; D. Miscellaneous; E. Normal. ${ }^{30}$

According to SCPE recommendations, if there are several patterns, the predominant pattern that is believed to be most likely to have led to the CP should be classified first; if there is another pathogenic pattern (A, B or C), this should be classified separately. Due to the myelination process development in the first years of life, SCPE recommends classifying MR images performed after the child has reached 2 years of age according to the MRICS system, unless the previous images revealed a particular pathology. ${ }^{30}$

Figure 2 presents selected examples of magnetic resonance imaging from the authors' own research.

Conventional MR imaging has limitations in delineating white matter tracts precisely. A powerful technique providing precise identification of white matter microstructure is diffusion tensor imaging (DTI). ${ }^{31}$

Diffusion tensor imaging captures restrictions in the random movement of water protons by macromolecules and myelin to visualize brain white matter tracts. It can be used to create two- and three-dimensional colour maps of normal white matter architecture and to provide more precise identification of white matter dysgenesis and injury than conventional imaging. ${ }^{31}$ DTI is unique in its ability to non-invasively visualize white matter fibre tracts in the human brain. It is effective in improving diagnostic accuracy and provides new information about the nature and extent of patterns of white matter cerebral abnormalities in children with $\mathrm{CP}^{31-33}$ It shows various white matter injury patterns in patients with PVL, with the most frequent injuries being to the retrolenticular part of the internal capsule, posterior thalamic radiation, superior corona radiata and commissural fibres. ${ }^{34}$ This method indicates that white matter tracts from both the somatosensory and motor cortex play an important role in the pathophysiology of motor disability in CP patients. ${ }^{35}$ DTI metrics (lower fractional anisotropy and higher transverse diffusivity) in the descending pyramidal tracts correlate with more significant motor impairment. ${ }^{31}$ DTI imaging also shows that the motor dysfunction in periventricular leukomalacia may, in part, reflect disruption of sensory connections outside the classic pyramidal motor pathways. $^{36}$

A meta-analysis of DTI studies published from January 1999 to January 2019 shows that fractional anisotropy (DTI metric) within the posterior part of the internal capsule is more closely related to motor dysfunction and can potentially be a biomarker for evaluating the degree of motor impairment in spastic cerebral palsy. ${ }^{37}$

The other neuroimaging modalities which can be used in CP patients are: magnetoencephalography (MEG), functional MRI (fMRI), and volumetric MRI of grey and white matter. There are multimodal studies that combine findings from different neuroimaging methods. The results of these studies could help in understanding the functional and structural changes in cerebral palsy. ${ }^{38-40}$

\section{Other Additional Examinations}

Due to the complexity of problems in the clinical presentation of CP, psychological tests, vision evaluation, audiometric tests and electroencephalography (EEG) are carried out. ${ }^{7}$ The value of EEG, in particular video EEG, cannot be overestimated in the differentiation of both non-epileptic paroxysmal disorders, including involuntary movements, and types of epileptic seizures in children suffering from CP and co-existing epilepsy.

\section{Age of Cerebral Palsy Diagnosis}

$\mathrm{CP}$ diagnosis is not easy - it must be preceded by an extensive interview, an analysis of the course of the child's development and the results of additional tests. It also requires a relatively long clinical observation period. To diagnose cerebral palsy, one needs to distinguish it from other motor disorders, with a different nature and course. Some neurodevelopmental disorders in early life can be temporary, whereas progressive motor disorders, at least in the first period of disease, can have a similar clinical presentation to that of $\mathrm{CP}$.

Taking into consideration the central nervous system maturation, brain plasticity and the changing clinical 

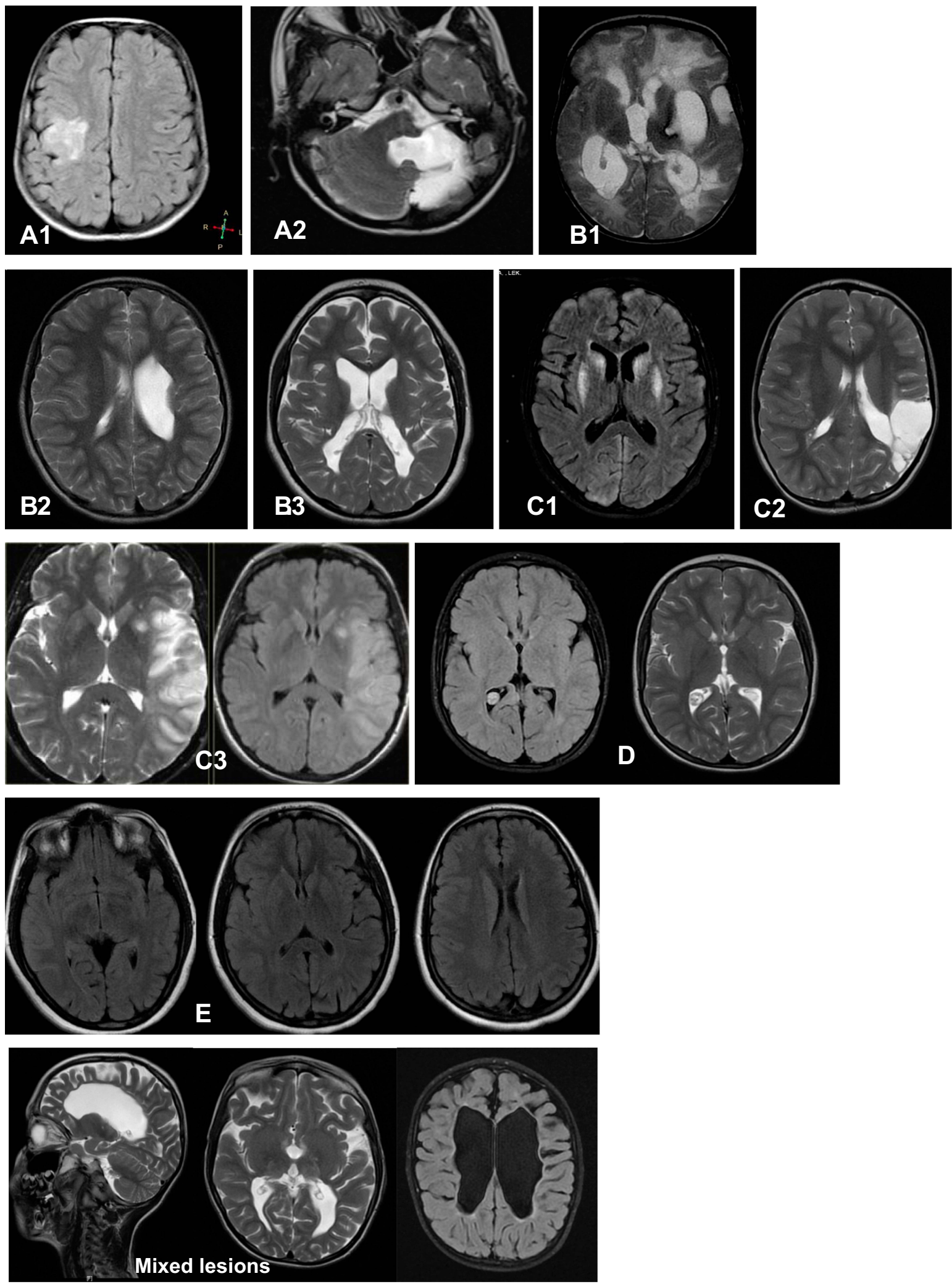

Figure 2 Selected examples of magnetic resonance imaging from own research are presented (MRI picture performed in Scanix (Katowice, Poland) presented by courtesy of center's Head Dr Magdalena Machnikowska-Sokolowska): A.I disorder of cortical formation; A.2 other maldevelopments; B.I PVL; B.2 sequelae of Intraventricular haemorrhage (IVH) or periventricular haemorrhagic infarction; B.3 combination of PVL and IHV sequelae; C.I basal ganglia/thalamus lesion; C.2 cortico-subcortical lesion; C.3 arterial infarction; $\mathbf{D}$ miscellaneous; $\mathbf{E}$ normal imaging.

Abbreviations: MRI, magnetic resonance imaging; PVL, periventricular leukomalacia; IVH, intraventricular hemorrhage. 
presentation, the final diagnosis of $\mathrm{CP}$, in particular of some of its types, cannot be made earlier than at a few years old. However, sometimes the symptoms indicating the possibility of $\mathrm{CP}$ are present already in early infancy. In such cases, delayed diagnosis can lead to a delay in undertaking proper treatment, and, in consequence, to the worse functioning of the child and his/her family in the future. There are various studies that examine diagnostic tools enabling an early diagnosis, especially in newborn babies belonging to the high-risk group, ie, premature patients, with a low birth weight or abnormalities in neuroimaging. In consequence, an early diagnosis allows for early implementation of medical interventions so as to optimize the motor and cognitive functions owing to brain plasticity, prevent secondary lesions, and improve the quality of the child's life, but also his/her well-being and the quality of life of his/her carers. ${ }^{41-43}$ Determining the precise age at which the final diagnosis of cerebral palsy should be made is an equivocal issue.

For the needs of international research programmes, based on registers of patients with CP in different parts of the world, such as the New South Wales CP Register, the Western Australian CP Register and SCPE, it was necessary to establish common criteria for CP diagnosis, and inclusion/exclusion criteria, including the criterion of age. The mutually agreed criterion of age allows for collecting all the data and confirming the diagnosis. In the majority of registering programmes, this age was established as 5 years. The final recommendation, however, is that the child should have reached 4 years of age in order to be properly diagnosed with $\mathrm{CP}^{44}$

\section{Other Medical Problems Co-Existing with Motor Disability in CP Patients \\ Epilepsy in Children with Cerebral Palsy}

Epilepsy is a separate, very important clinical problem in children with CP. Its incidence ranges from 15 to $55-60 \%$, and according to some authors, even up to $90-94 \%$ of children and adults with $\mathrm{CP}^{45-49}$ Epilepsy in children with $\mathrm{CP}$ is mostly revealed in the first 4-5 years of life, usually in the first year of life. ${ }^{46,50,51}$ The incidence of epilepsy varies depending on the type of cerebral palsy. Epilepsy is usually observed in tetraplegia (50-94\%); it frequently accompanies hemiplegia (33$50 \%$ ), but it seldom affects children suffering from diplegia and the ataxic type of CP (16-27\%). ${ }^{49}$

There are many studies concerning risk factors for epilepsy in children with CP. One of the significant factors is mental retardation..$^{45,47,48,50,52}$ It is estimated that more than $50 \%$ of children with $\mathrm{CP}$ and mental retardation suffer from epilepsy. The results of investigations also indicate a correlation between neonatal convulsions and a higher risk of epilepsy in children with $\mathrm{CP}^{47,48,50}$

A lot of data on the incidence of epilepsy, as well as the correlation between epilepsy and the course of the neonatal period, accompanying disorders and the type of $\mathrm{CP}$ was provided by population studies conducted by Sellier et al. They were based on SCPE registers from 17 regions and concerned children with CP born in the years 1976-1998. ${ }^{53}$ This research revealed a general trend for an increased incidence of epilepsy among children with CP in the years 1976-1983, followed by a drop in the years 1983-1998. Epilepsy usually occurred in children with the dyskinetic and bilaterally spastic type of CP and in children with accompanying vision and hearing disorders, mental retardation and the inability to walk. In the case of these children, epilepsy risk factors were brain development malformations, due date birth or moderately preterm birth (compared to very preterm birth), neonatal convulsions, artificial respiratory support, as well as treatment in an Intensive Care Unit. $^{53}$

Co-existence of epilepsy in a child with $\mathrm{CP}$ increases the risk of death, including so-called sudden unexpected death in epilepsy (SUDEP). This concept is understood as the sudden, unexpected death of a person suffering from epilepsy (in the presence of witnesses or without them), which is not related to an injury or drowning. Death occurs in "mild circumstances"; it may occur during a seizure or without one, but not in status epilepticus. Autopsy does not reveal the cause of death. The risk of SUDEP is the highest among young adults (aged 20-45) suffering from epilepsy. In the population of children, the risk of SUDEP is 10 times lower - it is estimated to reach 1.1-3.4/ 1000 ill children annually. ${ }^{54-56}$ The major risk factor for SUDEP is the high frequency of generalized tonic-clonic seizures as well as the presence of night seizures. Other risk factors include the early onset of epilepsy, male sex, mental retardation, long duration of illness, polytherapy, and prone position during sleep. ${ }^{57}$

\section{Mental Retardation}

Intellectual disability is an important and relatively common accompanying impairment in $\mathrm{CP}$ that has the potential to further affect daily activities, burden of care, quality of life, effectiveness of interventions, and longevity. ${ }^{58}$ Intellectual developmental disability is defined by significant delay in two or more developmental domains at less 
than 5 years old, and an intelligence quotient of 70 and below at an older age. ${ }^{9}$

The proportion of children with $\mathrm{CP}$ and intellectual impairment varies between $40 \%$ and $65 \% .{ }^{9,59,60}$ The frequency of intellectual disability has been reported to be relatively higher in association with quadriplegia, poor gross motor function, and epilepsy. ${ }^{58}$

There is also an association between epilepsy in children with cerebral palsy and the degree of mental impairment. The occurrence of epilepsy in $\mathrm{CP}$, mainly in children with hemiplegia and diplegia, is associated with reduced mental capacities. ${ }^{61}$

\section{Malnutrition and Gastrointestinal Complications}

The majority of children with cerebral palsy have feeding difficulties and gastrointestinal problems such as oropharyngeal dysfunction, gastroesophageal disease, and constipation. ${ }^{62}$ Oral feeding is a complex process requiring a mature sucking ability and an especially mature coordination of sucking with breathing and swallowing. ${ }^{63}$ Children with cerebral palsy often have difficulty with sucking. Nutritive sucking is a highly organized process that is essential for infants' feeding during the first 6 months of their lives. An infant's inability to perform a safe and successful oral feeding can be an early detector of immaturity of the central nervous system. ${ }^{63}$ A pilot study shows, using diffusion imaging, the relationship between nutritive sucking patterns and the microstructural integrity of sensory-motor tracts in newborns with brain injury. $^{64}$

Feeding difficulties among children with $\mathrm{CP}$ play an important role in the pathogenesis of malnutrition and increase the risk of growth failure. ${ }^{65}$ Physical growth is a fundamental measure of heath and well-being in children. ${ }^{66}$ Besides growth failure, the consequences of malnutrition include decreased cerebral function, impaired immune function, impaired circulation with poor wound healing, and diminished respiratory muscle strength. ${ }^{62}$

Oropharyngeal dysphagia is observed in 2 out of 3 children with $\mathrm{CP}$ and is known to influence not only their nutritional status, but also their respiratory health and parental stress. ${ }^{67}$ Researchers from Oxford in their study found that $20 \%$ of parents reported feeding as stressful or unenjoyable, with increased rates of stress with increasing gross motor impairment severity. ${ }^{68}$
In cerebral palsy, growth and nutrition disorders are common. They may be present among all children with $\mathrm{CP}$; however, they are more prominent among those with increasing severity of motor impairments. ${ }^{66}$

\section{Speech Problems}

Over $50 \%$ of children with CP exhibit some sort of speech impairment. ${ }^{69}$ Speech production involves respiration together with laryngeal, velopharyngeal and articulatory movements, and any of these functions may be hampered in CP. Motor disorders affecting speech include dysarthria/anarthria and dyspraxia/apraxia of speech. Dysarthria is characterized by slow, weak, imprecise and/or uncoordinated movements of the speech musculature. Apraxia/dyspraxia is characterized by a disturbance in the motor planning and programming of speech movements. ${ }^{70}$ Speech ability is related to the type of $\mathrm{CP}$, gross motor function, the presence of mental retardation and the localization of brain maldevelopment and lesions. ${ }^{70} \mathrm{An}$ association between the type of $\mathrm{CP}$ and speech ability was reported by Andersen et al in the Norwegian study. Ninety percent of the children with unilateral spastic CP had normal or understandable speech, while $97 \%$ of the children with dyskinetic $\mathrm{CP}$ had severely impaired or no speech. ${ }^{71}$

\section{Treatment of Motor Disorders in CP}

Care for a child with $\mathrm{CP}$ is a long-term process, aimed at ensuring the child and their family the best possible quality of life. Such a multi-directional approach includes comprehensive rehabilitation, specialist medical care as well as psychological and social support. ${ }^{72}$ The most important element of CP treatment is multi-faceted improvement. The major role in this improvement is played by systematic and comprehensive motor rehabilitation, individually tailored to the patient. Rehabilitation is based on so-called neuroplasticity, which is the ability of the nervous system to undergo permanent structural and functional changes in reaction to internal and external stimuli; it provides a foundation for learning and memorizing, as well as a basis for adaptation, developmental and compensation changes. It works in the case of both a damaged and undamaged brain, which "learns anew" as the result of rehabilitation. The greatest possibilities of modification occur at the earliest stages of development of the central nervous system (CNS). It is at this stage that the brain demonstrates a high degree of plasticity, which favours compensation of various deficiencies. For this reason, rehabilitation of children with $\mathrm{CP}$ risk factors should be started as soon as possible. ${ }^{42,43}$ Motor rehabilitation, ie, kinesiotherapy, involves restoring the lost 
motor patterns or developing new patterns that can compensate for the irretrievably lost functions through enforced motor activity. This is a major method of treating children with CP. An important rule to be followed in rehabilitation is the "developmental rule", which consists in learning subsequent motor skills that naturally appear at various stages of development, in their physiological sequence. There are many specialist neurophysiological methods of rehabilitation applied in CP. The two leading ones are: neurodevelopmental treatment (NDT, Bobath therapy), and reflex locomotion treatment (Vojta therapy).

Physiotherapy, massage, taping and orthopaedic appliances play an ancillary role in rehabilitation. ${ }^{73-79}$

The most frequent symptom in children with $\mathrm{CP}$ is spasticity, that is, a state of enhanced muscle tension, which limits the range of passive and active motion in joints and contributes to developing joint contractures. Spasticity has an adverse effect on the further development of motor functions. It hinders rehabilitation, care for patients and their self-care, causing pain, lower self-esteem and worse quality of life as well as contributing to permanent contractures, joint deformities, bedsores, thrombosis and infections. ${ }^{80}$ Treatment of spasticity involves systematic rehabilitation, if necessary, assisted by pharmacotherapy, physiotherapy or surgical interventions. Selection of a pharmacological treatment method depends on the intensity and location of the disease. In the case of generalized spasticity, the most frequently applied is general treatment. The main drugs used in this kind of treatment include baclofen - an analogue of gamma-aminobutyric acid (GABA), acting on the spinal cord, and benzodiazepine derivatives, such as diazepam, clonazepam or tetrazepam (these act on the central nervous system by releasing endogenic GABA). In the case of focal spasticity, one of the basic therapies is intramuscular administration of botulinum toxin type A (botulin). Botulinum toxin hinders the secretion of acetylcholine in neuromuscular junctions, resulting in a decrease of tension in the group of muscles subjected to treatment. Multi-level administration of botulinum toxin can be effective in the treatment of generalized spasticity. The improvement lasts approximately 3-8 months. At that time, systematic motor rehabilitation is necessary so as to make full use of the botulinum toxin effect. By reducing spasticity, botulinum toxin increases the range of passive and active motion, facilitates posture correction, and reduces discomfort and pain related to enhanced muscle tension, which is also felt during rehabilitation. Treatment with botulinum toxin results in a better quality of life for children with $\mathrm{CP}$, both in the case of focal spasticity being confined to single muscle groups, and generalized spasticity. Botulinum toxin can also reduce pain after orthopaedic operations in children with spastic types of $\mathrm{CP}^{81-86}$

In the case of patients for whom the above methods of spasticity treatment have proved ineffective, neurosurgical operations are performed, among others:

- continuous intrathecal infusion of baclofen through a pump

- selective dorsal rhizotomy: cutting of 50-75\% of the dorsal (afferent) nerve fibres on L1-S1 level; this treatment has a permanent and irreversible effect, reducing spasticity solely in the lower limbs

- selective peripheral neurotomy: cutting some of the fibres of the peripheral nerve innervating a particular muscle/group of muscles; it only affects the spasticity of the muscle innervated by the cut nerve fibres. ${ }^{87-89}$

Additional problems in cerebral palsy, such as gastroesophageal reflux, nutrition disorders, and constipation, require the use of specialist therapy methods, which are frequently surgical treatments. Most recently, the European Society for Paediatric Gastroenterology Hepatology and Nutrition (ESPGHAN) published guidelines for the evaluation and treatment of gastrointestinal and nutritional complications in children with neurological impairment. ${ }^{90}$ A huge role is played by the orthopaedic treatment of osteoarticular deformities. The therapeutic process often includes speech therapy for speech impediments and dysphagia. An important role is also played by the treatment of disorders in the cognitive sphere, and psychotherapy for emotional disorders in a sick child and their family.

Novak et al, ${ }^{91}$ in their systematic review study published in 2013, described systematically the best available intervention evidence for children with CP. The authors evaluated 64 different CP interventions reviewed across 131 intervention outcomes. The following CP interventions were shown to be effective ("green light go interventions"): 1) botulinum toxin, diazepam, selective dorsal rhizotomy for reducing muscle spasticity, 2) casting for improving and maintaining ankle range of motion, 3) hip surveillance for maintaining hip joint integrity, 4) constraint-induced movement therapy, bimanual training, context-focused therapy following botulinum toxin, home programmes for improving motor activity performance and/or self-care, 5) fitness training for improving fitness, 6) bisphosphonates for improving bone density, 7) pressure care for reducing the risk of pressure ulcers, 8) anticonvulsants for managing seizures. The following therapies were shown to be ineffective for improved motor activities and self-care in 
children with CP ("red light stop interventions"): craniosacral therapy, hip bracing, hyperbaric oxygen, neurodevelopmental therapy, sensory integration. The authors suggested that these interventions should be discontinued from $\mathrm{CP}$ care. $^{91}$

Still, both in papers published before 2013 and those published thereafter, contradictory opinions are found. ${ }^{76-79}$

\section{Treatment of Epilepsy in Cerebral Palsy}

The treatment of epilepsy in children with cerebral palsy is frequently a huge therapeutic challenge. The first choice in this treatment is pharmacotherapy. The effectiveness of pharmacological treatment of epilepsy in the group of children with cerebral palsy is lower than in the group of children with isolated epilepsy. ${ }^{92}$ Epilepsy in children with $\mathrm{CP}$ is frequently drug-resistant. The course of epilepsy and its treatment is largely dependent on the type and severity of CP. Drugresistant epilepsy is more often observed in children with spastic tetraplegia compared to other types of CP. According to the results of some studies, risk factors for drug-resistant epilepsy in children with $\mathrm{CP}$ include neonatal convulsions, intense neuropathological changes in cerebrum or mental retardation. $^{44-47}$

In the case of drug-resistant epilepsy, one should consider non-pharmacological methods of treatment, which include neurosurgical interventions and the ketogenic diet.

Neurosurgical interventions include operations and neuromodulation therapy. Surgeries can be causal or supportive. Causal therapies involve targeted resection of the epileptic focus and are aimed at freeing the patient of seizures. Supportive treatment is applied in the case of patients with drug-resistant epilepsy who cannot receive a causal therapy. It includes such methods as hemispherectomy, callosotomy, multiple subpial incisions, resection of the frontal part of the temporal lobe, selective resection of the amygdala and hippocampus as well as minimally invasive surgical techniques. Neuromodulation techniques include vagus nerve stimulation, trigeminal nerve stimulation, deep stimulation of the brain and reflex stimulation. In the case of patients with drug-resistant epilepsy who are not eligible for neurosurgical treatment, an alternative to pharmacological therapy is the ketogenic diet. ${ }^{93-100}$

The ketogenic diet is a specialized diet that involves highly restricted intake of carbohydrates and proteins and a high proportion of fat consumption. The precise mechanism of action of the ketogenic diet is not known, although many possible explanations have been proposed. There are many changes that occur in the body and brain as a result of the diet, but it is unclear which of these alterations is responsible for the anticonvulsant effect. It is becoming more apparent that the ketogenic diet likely works through multiple mechanisms that target fundamental biochemical pathways linked to cellular substrates (eg, ion channels) and mediators responsible for neuronal hyperexcitability. ${ }^{98}$

There are currently four ketogenic dietary therapies: the classic ketogenic diet, the modified Atkins diet, the mediumchain triglyceride diet and the low glycemic index treatment. Ketogenic diets are established, effective nonpharmacologic treatments for intractable epilepsy. They should be used in children after two anti-epileptic drugs have failed. ${ }^{101}$

\section{Conclusions}

Cerebral palsy is a complex problem as to definition, classification as well as treatment. Children at risk of CP due to common risk factors, such as prematurity, should be under special care to start early care for developmental support. CP comorbidities, especially epilepsy and malnutrition, should be diagnosed and supervised; proper control of $\mathrm{CP}$ comorbidities may pave the way to improve the development of children with $\mathrm{CP}$.

\section{Disclosure}

The authors report no conflicts of interest in this work.

\section{References}

1. Little WJ. The classic: hospital for the cure of deformities: course of lectures on the deformities of the human frame. 1843. Clin Orthop Relat Res. 2012;470(5):1252-1256. doi:10.1007/s11999-012-2302-y

2. Mac Keith RC, Mackenzie I, Polani P. The Little Club. Memorandum on terminology and classification of "cerebral palsy". Dev Med Child Neurol. 1959;1:27-35. doi:10.1111/j.1469-8749.1959.tb08073.x

3. Bax M. Terminology and classification of cerebral palsy. Dev Med Child Neurol. 1964;6:295-307. doi:10.1111/j.1469-8749.1964.tb10791.x

4. Mutch L, Alberman E, Hagberg B, Kodama K, Perat MV. Cerebral palsy epidemiology: where are we now and where are we going? Dev Med Child Neurol. 1992;34(6):547-551. doi:10.1111/j.1469-8749.1992.tb11479.x

5. Bax M, Goldstein M, Rosenbaum P, et al. Executive Committee for the Definition of Cerebral Palsy. Proposed definition and classification of cerebral palsy. Dev Med Child Neurol. 2005;47(8):571-576. doi:10.1017/ S001216220500112X

6. Rosenbaum P, Paneth N, Leviton A, et al. A report: the definition and classification of cerebral palsy. Dev Med Child Neurol. 2007;109:8-14.

7. Cans C, Dolk H, Platt MJ, Colver A, Prasauskiene A, Krageloh-Mann I; SCPE Collaborative group. Recommendations from the SCPE collaborative group for defining and classifying cerebral palsy. Dev Med Child Neurol Supp. 2007;109:35-38. doi:10.1111/j.1469-8749.2007.tb12626.x

8. Surveillance of Cerebral Palsy in Europe. Surveillance of cerebral palsy in Europe: a collaboration of cerebral palsy surveys and registers. Dev Med Child Neurol. 2000;42:816-824. doi:10.1017/ $\mathrm{S} 0012162200001511$ 
9. Leach EL, Shevell M, Bowden K, Stockler-Ipsiroglu S, van Karnebeek CD. Treatable inborn errors of metabolism presenting as cerebral palsy mimics: systematic literature review. Orphanet J Rare Dis. 2014;9:197. doi:10.1186/s13023-014-0197-2

10. Zouvelou V, Yubero D, Apostolakopoulou L, et al. The genetic etiology in cerebral palsy mimics: the results from a Greek tertiary care center. Eur J Paediatr Neurol. 2019;23(3):427-437. doi:10.1016/j.ejpn.2019.02.001

11. Hakami WS, Hundallah KJ, Tabarki BM. Metabolic and genetic disorders mimicking cerebral palsy. Neurosciences (Riyadh). 2019;24(3):155-163. doi:10.17712/nsj.2019.3

12. Pearson TS, Pons R, Ghaoui R, Sue CM. Genetic mimics of cerebral palsy. Mov Disord. 2019;34(5):625-636. doi:10.1002/mds.27655

13. Surveillance of Cerebral Palsy in Europe. Prevalence and characteristics of children with cerebral palsy in Europe. Dev Med Child Neurol. 2002;44:633-640.

14. Platt MJ, Cans C, Johnson A, et al. Trends in cerebral palsy among infants of very low birthweight $(<1500 \mathrm{~g})$ or born prematurely $(<32$ weeks) in 16 European centres: a database study. Lancet. 2007;6 (369):43-50.

15. Himpens E, Van den Broeck C, Oostra A, Calders P, Vanhaesebrouck P. Prevalence, type, distribution and severity of cerebral palsy in relation to gestational age: a meta-analytic review. Dev Med Child Neurol. 2008;50 (5):334-340. doi:10.1111/j.1469-8749.2008.02047.x

16. Oskoui M, Coutinho F, Dykeman J, Jette N, Pringsheim T. An update on the prevalence of cerebral palsy: a systematic review and meta-analysis. Dev Med Child Neurol. 2013;55(6):509-519. doi:10.1111/dmcn. 12080

17. Sellier E, Platt MJ, Andersen GL, Krageloh-Mann I, De La Cruz J, Cans C, on behalf of Surveillance of Cerebral Palsy Network. Decreasing prevalence in cerebral palsy: a multi- site European population- based study, 1980 to 2003. Dev Med Child Neurol. 2016;58(1):85-92. doi:10.1111/dmcn.12865

18. Reddihough D, Collins KJ. The epidemiology and causes of cerebral palsy. Aust J Physiother. 2003;49(1):7-12. doi:10.1016/S00049514(14)60183-5

19. Kułak W, Sobaniec W, Okurowska-Zawada B, Sienkiewicz D, Paszko-Patej G. Antenatal, intrapartum and neonatal risk factors for cerebral palsy in children in Podlaskie Province. Neurol Dziec. 2009;18(36):19-24.

20. McIntyre S, Taitz D, Koegh J, Goldsmith S, Badawi N, Blair E. A systematic review of risk factors for cerebral palsy in children born at term in developed countries. Dev Med Child Neurol. 2013;55:499-508. doi:10.1111/dmcn.12017

21. Linsell L, Malouf R, Morris J, Kurinczuk JJ, Marlow N. Prognostic factors for cerebral palsy and motor impairment in children born very preterm or very low birthweight: a systematic review. Dev Med Child Neurol. 2016;58:554-569. doi:10.1111/ dmen.12972

22. Ahlin K, Himmelmann K, Hagberg G, et al. Non-infectious risk factors for different types of cerebral palsy in term-born babies: a population-based, case-control study. BJOG. 2013;120(6):724-731. doi:10.1111/1471-0528.12164

23. Goldsmith S, McIntyre S, Badawi N, Hansen M. Cerebral palsy after assisted reproductive technology: a cohort study. Dev Med Child Neurol. 2018;60(1):73-80. doi:10.1111/dmcn.13577

24. Balf CL, Ingram TTS. Problems in the classification of cerebral palsy in childhood. Br Med J. 1955;16:163-166. doi:10.1136/bmj.2.4932.163

25. Hagberg G, Hagberg B, Olow I. The changing panorama of cerebral palsy in Sweden 1954-1970. III. The importance of fetal deprivation of supply. Acta Paediatr Scand. 1976;65:403-408. doi:10.1111/j.1651-2227.1976.tb04906.x

26. Palisano RJ, Cameron D, Resenbaum PL, Walter SD, Rusell D. Stability of the gross motor function classification system. Dev Med Child Neurol. 2006;48(6):424-428. doi:10.1017/S0012162206000934
27. Palisano RJ, Rosenbaum PL, Bartlett D, Livingston MH. Content validity of the expanded and revised gross motor function classification system. Dev Med Child Neurol. 2008;50(10):744-750. doi:10.1111/j.1469-8749.2008.03089.x

28. Elvrum AK, Andersen GL, Himmelmann K, et al. Bimanual Fine Motor Function (BFMF) classification in children with cerebral palsy: aspects of construct and content validity. Phys Occup Ther Pediatr. 2016;36(1):1-16. doi:10.3109/ 01942638.2014.975314

29. Ohrvall AM, Krumlinde-Sundhomr L, Eliasson AC. The stability of manual ability classification system over time. Dev Med Child Neurol. 2014;56(2):185-189. doi:10.1111/dmcn.12348

30. Himmelmann K, Horber V, De la Cruz J, et al; SCPE Working Group. MRI classification system (MRICS) for children with cerebral palsy: development, reliability and recommendations. Dev Med Child Neurol. 2017;59(1):57-64. doi:10.1111/ dmcn.13166

31. Hoon AH Jr, Stashinko EE, Nagae LM, et al. Sensory and motor deficits in children with cerebral palsy born preterm correlate with diffusion tensor imaging abnormalities in thalamocortical pathways. Dev Med Child Neurol. 2009;51(9):697-704. doi:10.11 11/j.1469-8749.2009.03306.x

32. Jiang H, Li X, Jin C, et al. Early diagnosis of spastic cerebral palsy in infants with periventricular white matter injury using diffusion tensor imaging. Am $J$ Neuroradiol. 2019;40(1):162-168. doi:10.31 74/ajnr.A5914

33. Papadelis C, Ahtam B, Feldman HA, et al. Altered white matter connectivity associated with intergyral brain disorganization in hemiplegic cerebral palsy. Neuroscience. 2019;399:146-160. doi:10.1016/j.neuroscience.2018.12.028

34. Nagae LM, Hoon AH Jr, Stashinko E, et al. Diffusion tensor imaging in children with periventricular leukomalacia: variability of injuries to white matter tracts. Am J Neuroradiol. 2007;28 (7):1213-1222. doi:10.3174/ajnr.A0534

35. Trivedi R, Agarwal S, Shah V, et al. Correlation of quantitative sensorimotor tractography with clinical grade of cerebral palsy. Neuroradiology. 2010;52(8):759-765. doi:10.1007/s00234-010-0703-8

36. Hoon AH Jr, Lawrie WT Jr, Melhem ER, et al. Diffusion tensor imaging of periventricular leukomalacia shows affected sensory cortex white matter pathways. Neurology. 2002;59(5):752-756. doi:10.1212/wnl.59.5.752

37. Jiang H, Liu H, He H, et al. Specific white matter lesions related to motor dysfunction in spastic cerebral palsy: a meta-analysis of diffusion tensor imaging studies. J Child Neurol. 2020;35(2)::146-154. doi: $10.1177 / 0883073819879844$

38. Papadelis C, Butler EE, Rubenstein M, et al. Reorganization of the somatosensory cortex in hemiplegic cerebral palsy associated with impaired sensory tracts. Neuroimage Clin. 2017;17:198-212. doi:10.1016/j.nicl.2017.10.021

39. Papadelis C, Ahtam B, Nazarova M, et al. Cortical somatosensory reorganization in children with spastic cerebral palsy: a multimodal neuroimaging study. Front Hum Neurosci. 2014;8:725. doi:10.33 89/fnhum.2014.00725

40. Papadelis C, Kaye H, Shore B, Snyder B, Grant PE, Rotenberg A. Maturation of corticospinal tracts in children with hemiplegic cerebral palsy assessed by diffusion tensor imaging and transcranial magnetic stimulation. Front Hum Neurosci. 2019;13:254. doi:10. 3389/fnhum.2019.00254

41. Bosanquet M, Copeland L, Ware R, Boyd R. A systematic review of tests to predict cerebral palsy in young children. Dev Med Child Neurol. 2013;55(5):418-426. doi:10.1111/dmcn.12140

42. Granild- Jensen JB, Rackauskaite G, Flachs EM, Uldall P. Predictors for early diagnosis of cerebral palsy from national registry data. Dev Med Child Neurol. 2015;57(10):931-935. doi:10. $1111 /$ dmcn. 12760 
43. Novak I, Morgan C, Adde L, et al. Early, accurate diagnosis and early intervention in cerebral palsy: advances in diagnosis and treatment. JAMA Pediatr. 2017;171(9):897-907. doi:10.5167/uzh149328

44. Smithers-Sheedy H, Badawi N, Blair E, et al. What constitutes cerebral palsy in the twenty-first century? Dev Med Child Neurol. 2014;56:323-328. doi:10.1111/dmcn. 12262

45. Kwong KL, Wong SK, Kwan T. Epilepsy in children with cerebral palsy. Pediatr Neurol. 1998;19(1):31-36. doi:10.1016/S0887-8994 (98)00011-3

46. Gururaj AK, Sztriha L, Bener A, Dawodu A, Aepen V. Epilepsy in children with cerebral palsy. Seizure. 2003;12(2):110-114. doi:10. 1016/S1059131102002558

47. Kułak W, Sobaniec W. Risk factors and prognosis of epilepsy in children with cerebral palsy in north-eastern Poland. Brain Dev. 2003;25(7):499-506. doi:10.1016/S0387-7604(03)00040-8

48. Mert GG, Incecik F, Altunbasak S, et al. Factors affecting epilepsy development and epilepsy prognosis in cerebral palsy. Pediatr Neurol. 2011;45(2):89-94. doi:10.1016/j.pediatrneurol.2011.03.001

49. Wallace SJ. Epilepsy in cerebral palsy. Dev Med Child Neurol. 2001;43(10):713-717. doi:10.1111/j.1469-8749.2001.tb00147.x

50. Bruck I, Antoniuk SA, Spessatto A, Schmitt de Bem R, Hausberger R, Pacheco CG. Epilepsy in children with cerebral palsy. Arq Neuropsiquiatr. 2001;59(1):35-39. doi:10.1590/S0004282X2001000100008

51. Singhi P, Jagirdar S, Khandelwai N, Malhi P. Epilepsy in cerebral palsy. J Child Neurol. 2003;18(3):174-179. doi:10.1177/0883073 8030180030601

52. Zafeiriou DI, Kontopoulos EE, Tsikoulas I. Characteristics and prognosis of epilepsy in children with cerebral palsy. $J$ Child Neurol. 1999;14(5):289-294. doi:10.1177/088307389901400504

53. Sellier E, Uldall P, Calado E, et al. Epilepsy and cerebral palsy: characteristics and trends in children born in 1976-1998. Eur J Paediatr Neurol. 2012;16(1):48-55. doi:10.1016/j.ejpn.2011.10.003

54. Donner EJ, Camfield P, Brooks L, et al. Understanding death in children with epilepsy. Pediatr Neurol. 2017;70:7-15. doi:10.1016/ j.pediatrneurol.2017.01.011

55. Devinsky O, Hesdorffer DC, Thurman DJ, Lhatoo S, Richerson G Sudden unexpected death in epilepsy: epidemiology, mechanisms and prevention. Lancet Neurol. 2016;15(10):1075-1088. doi:10.10 16/S1474-4422(16)30158-2

56. Shankar R, Donner EJ, McLean B, Nashef L, Tomson T. Sudden unexpected death in epilepsy (SUDEP): what every neurologist should know. Epileptic Disord. 2017;19(1):1-9. doi:10.1684/epd. 2017.0891

57. Harden C, Tomson R, Gloss D, et al. Practice guideline summary: sudden unexpected death in epilepsy incidence rates and risk factors: report of the guideline development, dissemination, and implementation subcommittee of the American Academy of Neurology and the American Epilepsy Society. Neurology. 2017;88:1674-1680. doi:10.1212/WNL.0000000000003685

58. Reid SM, Meehan EM, Arnup SJ, Reddihough DS. Intellectual disability in cerebral palsy: a population-based retrospective study. Dev Med Child Neurol. 2018;60(7):687-694. doi:10.1111/ dmcn. 13773

59. Türkoğlu G, Türkoğlu S, Çelik C, Uçan H. Intelligence, functioning and related factors in children with cerebral palsy. Noro Psikiyatr Ars. 2017;54(1):33-37. doi:10.5152/npa.2015.12676

60. Sigurdardottir S, Eiriksdottir A, Gunnarsdottir E, Meintema M, Arnadottir U, Vik T. Cognitive profile in young Icelandic children with cerebral palsy. Dev Med Child Neurol. 2008;50(5):357-362. doi:10.1111/j.1469-8749.2008.02046.x

61. Gajewska E, Sobieska M, Samborski W.Associations between manual abilities, gross motor function, epilepsy, and mental capacity in children with cerebral palsy. Iran J Child Neurol. 2014;8 (2):45-52.
62. Trivic I, Hojsak I. Evaluation and treatment of malnutrition and associated gastrointestinal complications in children with cerebral palsy. Pediatr Gastroenterol Hepatol Nutr. 2019;22(2):122-131. doi:10.5223/pghn.2019.22.2.122

63. Tamilia E, Taffoni F, Formica D, et al. Technological solutions and main indices for the assessment of newborns' nutritive sucking: a review. Sensors (Basel). 2014;14(1):634-658. doi:10.3390/s140100634

64. Tamilia E, Parker MS, Rocchi M, et al. Nutritive sucking abnormalities and brain microstructural abnormalities in infants with established brain injury: a pilot study. $J$ Perinatol. 2019;39 (11):1498-1508. doi:10.1038/s41372-019-0479-6

65. Karim T, Jahan I, Dossetor R, et al. Nutritional status of children with cerebral palsy- findings from prospective hospital- based surveillance in vietnam indicate a need for action. Nutrients. 2019;11(9):E2132. doi:10.3390/nu11092132

66. Kuperminc MN, Stevenson RD. Growth and nutrition disorders in children with cerebral palsy. Dev Disabil Res Rev. 2008;14:2. doi:10.1002/ddrr.14

67. Benfer KA, Weir KA, Bell KL, et al. Oropharyngeal dysphagia and cerebral palsy. Pediatrics. 2017;140(6):e20170731. doi:10.1542/ peds.2017-0731

68. Sullivan PB, Lambert B, Rose M, Ford-Adams M, Johnson A, Griffiths P. Prevalence and severity of feeding and nutritional problems in children with neurological impairment: oxford feeding study. Dev Med Child Neurol. 2000;42(10):674-680. doi:10.1111/ j.1469-8749.2000.tb00678.x

69. Darling-White M, Sakash A, Hustad KC. Characteristics of speech rate in children with cerebral palsy: a longitudinal study. $J$ Speech Lang Hear Res. 2018;61:2502-2515. doi:10.1044/2018_JSLHRS-17-0003

70. Nordberg A, Miniscalco C, Lohmander A, Himmelmann K. Speech problems affect more than one in two children with cerebral palsy: Swedish population- based study. Acta Paediatr. 2013;102:161-166. doi:10.1111/apa.12076

71. Andersen GL, Irgens LM, Haagaas I, Skranes JS, Meberg AE, Vik T. Cerebral palsy in Norway: prevalence, subtypes and severity. Eur J Paediatr Neurol. 2008;12:4-13. doi:10.1016/j.ejpn.2007.05.001

72. Trabacca A, Vespino T, Di Liddo A, Russo L. Multidisciplinary rehabilitation for patients with cerebral palsy: improving long-term care. J Multidiscip Healthc. 2016;9:455-462. doi:10.2147/JMDH. S88782

73. Mundkur N. Neuroplasticity in children. Indian J Pediatr. 2005;72 (10):855-857. doi:10.1007/bf02731115

74. Reid LB, Rose SE, Boyd RN. Rehabilitation and neuroplasticity in children with unilateral cerebral palsy. Nat Rev Neurol. 2015;11 (7):390-400. doi:10.1038/nrneurol.2015.97

75. Sterling C, Taub E, Davis D, et al. Structural neuroplastic change after constraint-induced movement therapy in children with cerebral palsy. Pediatrics. 2013;131:1664-1669. doi:10.1542/peds.201 2-2051

76. Klimont L. Principles of Bobath neuro-developmental therapy in cerebral palsy. Ortop Traumatol Rehabil. 2001;3(4):527-530.

77. Yalcinkaya EY, Caglar NS, Tugcu B, Ronbaklar A. Rehabilitation outcomes of children with cerebral palsy. J Phys Ther Sci. 2014;26 (2):285-289. doi:10.1589/jpts.26.285

78. Lee KH, Park JW, Lee HJ, et al. Efficacy of intensive neurodevelopmental treatment for children with developmental delay, with or without cerebral palsy. Ann Rehabil Med. 2017;41(1):90-96. doi:10.5535/arm.2017.41.1.90

79. Tekin F, Kavlak E, Cavlak U, Altug F. Effectiveness of neuro-developmental treatment (Bobath Concept) on postural control and balance in cerebral palsied children. J Back Musculoskelet Rehabil. 2018;31(2):397-403. doi:10.3233/BMR-170813

80. Massagli TL. Spasticity and its management in children. Phys Med Rehabil Clin N Am. 1991;2(4):867-889. doi:10.1016/S1047-96 51(18)30686-7 
81. Pin TW, Elmasry J, Lewis J. Efficacy of botulinum toxin A in children with cerebral palsy in gross motor function classification system levels IV and V: a systematic review. Dev Med Child Neurol. 2013;55 (4):304-313. doi:10.1111/j.1469-8749.2012.04438.x

82. Barwood S, Baillieu C, Boyd R, et al. Analgesic effects of botulinum toxin A: a randomized, placebo- controlled clinical trial. Dev Med Child Neurol. 2000;42(2):116-121. doi:10.1111/j.14698749.2000.tb00056.x

83. Delgado MR, Hirtz D, Aisen M, et al. Report of the quality standards subcommittee of the American Academy of Neurology and the Practice Committee of the Child Neurology Society. Practice parameter: pharmacologic treatment of spasticity in children and adolescents with cerebral palsy (an evidence-based review). Neurology. 2010;74: 336-343. doi:10.1212/WNL.0b013e3181cbcd2f

84. Chung CY, Chen CL, Wong AM. Pharmacotherapy of spasticity in children with cerebral palsy. J Formos Med Assoc. 2011;110 (4):215-222. doi:10.1016/S0929-6646(11)60033-8

85. Balaban B, Tok F, Tan A, Matthews D. Botulinum toxin a treatment in children with cerebral palsy: its effects on walking and energy expenditure. Am J Phys Med Rehabil. 2012;91(1):53-64. doi:10. 1097/PHM.0b013e31823caae1

86. Lowing K, Thews K, Haglund-Akerlind Y, Gutierrez-Farewik EM. Effects of botulinum toxin-A and goal-directed physiotherapy in children with cerebral palsy GMFCS levels I \& II. Phys Occup Ther Pediatr. 2017;37(3):268-282. doi:10.3109/01942638.2016.1150384

87. Overgard TM, Kjaersgaard-Hansen L, Soe M, Illum NO. Positive experience with intrathecal baclofen treatment in children with severe cerebral palsy. Dan Med J. 2015;62(1):A4999.

88. Wang KK, Munger ME, Chen BP-J, Novacheck TF. Selective dorsal rhizotomy in ambulant children with cerebral palsy. J Child Orthop. 2018;12(5):413-427. doi:10.1302/1863-2548.12.180123

89. Msaddi AK, Mazroue AR, Shahwan S, et al. Microsurgical selective peripheral neurotomy in the treatment of spasticity in cerebral-palsy children. Stereotact Funct Neurosurg. 1997;69: 251-258. doi:10.1159/000099884

90. Romano C, van Wynckel M, Huls J, et al. European society for paediatric gastroenterology, hepatology and nutrition guidelines for the evaluation and treatment of gastrointestinal and nutritional complications in children with neurological impairment. J Pediatr Gastroenterol Nutr. 2017;65:242-264. doi:10.1097/MPG.0000000000001646
91. Novak I, McIntyre S, Morgan C, et al. A systematic review of interventions for children with cerebral palsy: state of the evidence. Dev Med Child Neurol. 2013;55(10):885-910. doi:10.1111/dmcn. 12246

92. Mazurkiewicz- Bełdzińska M, Szmuda M, Matheisel A, Wendorff J, Gniadkowska-Nowakowska A. Epilepsy in cerebral palsy. Comprehensive questionnaire research performed in three different provinces in Poland. Neurol Dziec. 2007;16(32):35-38.

93. LaRiviere MJ, Gross RE. Stereotactic laser ablation for medically intractable epilepsy: the next generation of minimally invasive epilepsy surgery. Front.Surg. 2016;3:64. doi:10.3389/fsurg.2016. 00064

94. Bandt SK, Leuthardt EC. minimally invasive neurosurgery for epilepsy using stereotactic MRI guidance. Neurosurg Clin N Am. 2016;27(1):51-58. doi:10.1016/j.nec.2015.08.005

95. Kovac S, Vakharia VN, Scott C, Diehl B. Invasive epilepsy surgery evaluation. Seizure. 2017;44:125-136. doi:10.1016/j.seizure.2016. 10.016

96. Camp C, Smithson WH, Bunker M, Burke T, Hughes D. Impact of vagus nerve stimulation on secondary care burden in children and adults with epilepsy: review of routinely collected hospital data in England. Epilepsy Behav. 2015;52(Pt A):68-73. doi:10.1016/j. yebeh.2015.08.026

97. Qualmann KJ, Spaeth CG, Myers MF, et al. Pediatric epilepsy surgery: the prognostic value of central nervous system comorbidities in patients and their families. Child Neurol. 2017;32 (5):467-474. doi:10.1177/0883073816685653

98. Rho JM. How does the ketogenic diet induce anti-seizure effects? Neurosci Lett. 2017;637:4-10. doi:10.1016/j.neulet.2015.07.034

99. Martin K, Jackson CF, Lewy RG, Cooper PN. Ketogenic diet and other dietary treatments for epilepsy. Cochrane Database Syst Rev. 2016;2. doi:10.1002/14651858.CD001903.pub3

100. Jekovec-Vrhovsek M. Epilepsy in children with cerebral palsy. East J Med. 2012;17:166-170.

101. Kossoff EH, Zupec-Kania BA, Auvin S, et al.; the Practice Committee of the Child Neurology Society. Optimal clinical management of children receiving dietary therapies for epilepsy: updated recommendations of the International Ketogenic Diet Study Group. Epilepsia Open. 2018;3(2):174-192. doi:10.1002/ epi4.12225.
Neuropsychiatric Disease and Treatment

\section{Publish your work in this journal}

Neuropsychiatric Disease and Treatment is an international, peerreviewed journal of clinical therapeutics and pharmacology focusing on concise rapid reporting of clinical or pre-clinical studies on a range of neuropsychiatric and neurological disorders. This journal is indexed on PubMed Central, the 'PsycINFO' database and CAS, and

\section{Dovepress}

is the official journal of The International Neuropsychiatric Association (INA). The manuscript management system is completely online and includes a very quick and fair peer-review system which is all easy to use. Visit http://www.dovepress.com/testimonials.php to read real quotes from published authors. 